
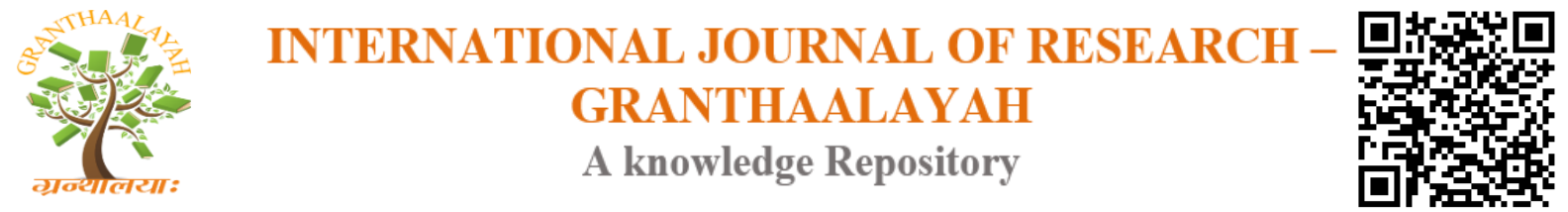

Science

\title{
THE PREDICTION OF THE THERMOHYDROGRAVIDYNAMIC THEORY CONCERNING THE STRONGEST INTENSIFICATIONS OF THE GLOBAL NATURAL PROCESSES OF THE EARTH SINCE 18 JULY, 2017 AND BEFORE 26 FEBRUARY, 2018
}

\author{
Dr. Sergey V. Simonenko *1 \\ ${ }^{*}$ V.I. Il'ichev Pacific Oceanological Institute, Far Eastern Branch of Russian Academy of \\ Sciences, Vladivostok, Russia
}

\begin{abstract}
The article presents (on 21 August, 2017) the prediction of the established global prediction thermohydrogravidynamic principle (of the developed thermohydrogravidynamic theory containing the cosmic geophysics and the cosmic seismology based on the author's generalization of the first law of thermodynamics for non-stationary cosmic gravitation) concerning the strongest intensifications (since 18 July, 2017 and before 26 February, 2018) of the global seismotectonic, volcanic, climatic and magnetic processes of the Earth determined by the maximal (near 7 November, 2017) combined integral energy gravitational influence on the internal rigid core of the Earth (and on the Earth as a whole) of the planets (Mercury, Venus, Mars and Jupiter) and the Sun due to the gravitational interactions of the Sun with Jupiter Saturn, Uranus and Neptune. The prediction is based on the established global prediction thermoshydrogravidynamic principle (used for the considered real planetary configurations of the Earth and the planets of the Solar System during the range 2004 2017) and on the statistical analysis of the previous strongest earthquakes occurred near the calculated dates of the local maximal combined planetary and solar integral energy gravitational influences (during the range 2004 2016) on the internal rigid core of the Earth.
\end{abstract}

Keywords: Thermohydrogravidynamic Theory; Cosmic Seismology; Cosmic Gravitation; Seismotectonic; Volcanic and Climatic Disasters.

Cite This Article: Dr. Sergey V. Simonenko. (2017). "THE PREDICTION OF THE THERMOHYDROGRAVIDYNAMIC THEORY CONCERNING THE STRONGEST INTENSIFICATIONS OF THE GLOBAL NATURAL PROCESSES OF THE EARTH SINCE 18 JULY, 2017 AND BEFORE 26 FEBRUARY, 2018." International Journal of Research - Granthaalayah, 5(8), 127-145. https://doi.org/10.29121/granthaalayah.v5.i8.2017.2199.

\section{Introduction}

The predictions of the strongest sesmotectonic [1-4], volcanic [4, 5], climatic [4, 6, 7] and geomagnetic [8-13] processes of the Earth are the urgent problems [14-16] for humankind before 
the founded $[15,16]$ increased intensifications (during the ranges $2020 \div 2026,2037.38 \div 2043.38$ and $2055 \div 2064$ ) of the global natural (sesmotectonic, volcanic, climatic and magnetic) processes $[15,16]$ of the Earth. We expanded the thermohydrogravidynamic theory [2-4, 7, 13-17] of the global natural processes of the Earth to the thermohydrogravielectromagnetic theory [13, 15] of the controlled thermonuclear reactions [13, 18-20] related [13] with the problem [8-12] of the geomagnetic reversals. In this article, we present (to the International Journal of Research GRANTHAALAYAH) the prognosticating deductions of the thermohydrogravidynamic theory [2-4, 7, 13-17] of the global natural processes concerning the different forthcoming ranges (characterized by the calculated probabilities) of the strongest intensifications of the global natural (sesmotectonic, volcanic, climatic and magnetic) processes of the Earth since 18 July, 2017 and before 26 February, 2018.

In Section 2 we present the established generalized formulations (1) and (5) of the first law of thermodynamics [2-4, 7, 13-17, 21] for the symmetric stress tensor $\mathbf{T}$ [22] and the established $[15,16,23]$ global prediction thermohydrogravidynamic principles (8) and (9) determining the maximal temporal intensifications of the global and regional natural (sesmotectonic, volcanic, climatic and magnetic) processes of the Earth related with the maximal and minimal combined cosmic integral energy gravitational influences ((8) and (9), respectively, for the time moments $\mathrm{t}=\mathrm{t}^{*}\left(\tau_{\mathrm{c}, \mathrm{r}}\right)$ and $\mathrm{t}=\mathrm{t}_{*}\left(\tau_{\mathrm{c}, \mathrm{r}}\right)$ ) on the considered internal rigid core $\tau_{\mathrm{c}, \mathrm{r}}$ (of the Earth) subjected to the combined cosmic integral energy gravitational influence of the planets of the Solar System, the Moon and the Sun (owing to the gravitational interaction of the Sun with the outer large planets).

In Section 3 we present the previous confirmed prediction [23] (based on the global prediction thermohydrogravidynamic principle (8)) concerning the past strongest intensifications of the global natural (sesmotectonic, volcanic, climatic and magnetic) processes of the Earth (in 2016 since 1 September, 2016 and before 26 January, 2017) determined by the maximal (for the time moment $\mathrm{t}^{*}\left(\tau_{\mathrm{c}, \mathrm{r}}, 2016\right)=2016.7666$, which corresponds approximately to 6 October, 2016) combined planetary and solar integral energy gravitational influences on the internal rigid core $\tau_{\mathrm{c}, \mathrm{r}}$ of the Earth. In Section 3 we present also the new prediction (based on the global prediction thermohydrogravidynamic principle (8)) concerning the strongest intensifications of the global natural (sesmotectonic, volcanic, climatic and magnetic) processes of the Earth (since 18 July, 2017 and before 26 February, 2018) determined by the maximal (for the time moment $\mathrm{t}^{*}\left(\tau_{\mathrm{c}, \mathrm{r}}, 2017\right)=2017.85$, which corresponds approximately to 7 November, 2017) combined planetary and solar integral energy gravitational influences on the internal rigid core $\tau_{\mathrm{c}, \mathrm{r}}$ of the Earth.

In Section 4 we present the confirmed [23] validity of the established [15, 16, 23] global prediction thermohydrogravidynamic principle (8) (of the thermohydrogravidynamic theory [2$4,7,13-17,21,23]$ ) concerning the predicted strongest intensifications of the global natural (sesmotectonic and climatic) processes of the Earth in 2016 since 1 September, 2016 and before 26 January, 2017. In Section 4 we present (on 31 August, 2017 during the date of the second submission of the corrected article for publication to the International Journal of Research GRANTHAALAYAH) the existing (for 31 August, 2017) facts and evidences confirming the 
validity of the established $[15,16,23]$ global prediction thermohydrogravidynamic principle (8) (of the thermohydrogravidynamic theory [2-4, 7, 13-17, 21, 23]) concerning the second subrange of the strongest (in 2017) intensifications of the global natural (seismotectonic, volcanic and climatic) processes of the Earth since 18 July, 2017 and before 26 February, 2018.

In Section 5 we present the conclusions.

\section{Methodology}

Based on the general equation of continuum movement [22], the classical differential formulation [24] of the first law of thermodynamics for the one-component macrodifferential continuum element, the decomposition $\mathbf{P}=\mathrm{p} \boldsymbol{\delta}+\boldsymbol{\Pi}$ [24] for the pressure tensor $\mathbf{P}$ [22], the viscous-stress tensor $\boldsymbol{\Pi}$ [24] and the symmetric stress tensor $\mathbf{T}=-\mathbf{P}$ [22] ( $\boldsymbol{\delta}$ is the Kronecker delta-tensor, $\mathrm{p}$ is the thermodynamic pressure), we derived [2-4, 7, 13-17, 23, 25] the generalized differential formulation of the first law of thermodynamics (for individual finite continuum region $\tau$ considered in a Galilean frame of reference with respect to a Cartesian coordinate system $K$ shown on Fig. 1):

$$
\mathrm{dU}_{\tau}+\mathrm{dK}_{\tau}+\mathrm{d} \pi_{\tau}=\delta \mathrm{Q}+\delta \mathrm{A}_{\mathrm{np}, \boldsymbol{} \tau}+\mathrm{dG}
$$

where $\delta Q$ is the classical $[22,24,26,27]$ infinitesimal change of heat across the continuum boundary surface $\partial \tau$ of the continuum region $\tau, \mathrm{dU}_{\tau}$ is the classical $[22,24,26,27]$ infinitesimal change of the internal thermal energy $U_{\tau}, \mathrm{dK}_{\tau}$ is the established $[2-4,7,13-17,23]$ infinitesimal increment of the macroscopic kinetic energy $K_{\tau}[21,28]$ of the continuum region $\tau, \mathrm{d} \pi_{\tau}$ is the established [2-4, 7, 13-17, 23] infinitesimal increment of the gravitational potential energy $\pi_{\tau}$ determined by the potential $\psi$ of the combined (cosmic and terrestrial) non-stationary gravity field, $\delta \mathrm{A}_{\mathrm{np}, \partial \tau}$ is the generalized $[2-4,7,14,21]$ infinitesimal work done by non-potential terrestrial stress forces acting on the continuum boundary surface $\partial \tau$ of the continuum region $\tau$,

$$
\mathrm{dG}=\mathrm{dt} \iiint_{\tau} \frac{\partial \psi}{\partial \mathrm{t}} \rho \mathrm{dV}
$$

is the established [2-4, 7, 13-17, 23] infinitesimal combined (cosmic and terrestrial) nonstationary energy gravitational influence on the continuum region $\tau$ during the infinitesimal time interval dt. The relation (2) for $\mathrm{dG}$ takes into account the partial derivative $\partial \psi / \partial \mathrm{t}$ of the potential $\psi$ of the combined (cosmic and terrestrial) non-stationary gravitational field, the local mass density $\rho$ of the differential volume $\mathrm{dV}$ in the continuum region $\tau$.

The generalized differential formulation (1) of the first law of thermodynamics and the relation (2) result to the following relation:

$$
\mathrm{dG}=\mathrm{dt} \iiint_{\tau} \frac{\partial \psi}{\partial \mathrm{t}} \rho \mathrm{dV}=-\mathrm{dt} \iint_{\partial \tau}\left(\mathbf{J}_{\mathrm{g}} \cdot \mathbf{n}\right) \mathrm{d} \Omega_{\mathbf{n}},
$$

which is the theoretical foundation $[3,4,15,16,23]$ of the power $\mathbf{J}_{\mathrm{g}}$ of the gravitational energy (of the detected [1] non-relativistic classical "gravitational" waves $[3,4,15,16]$ generated from 
the focal regions of earthquakes) across the surface element $\mathrm{d} \Omega_{\mathrm{n}}$ determined by the external normal unit vector $\mathbf{n}$. This theoretical foundation is based on the relation $[3,4,15-17,23]$ for the divergence $\operatorname{div} \mathbf{J}_{\mathrm{g}}$ :

$$
\operatorname{div} \mathbf{J}_{\mathrm{g}}=-\rho \frac{\partial \psi}{\partial \mathrm{t}}
$$

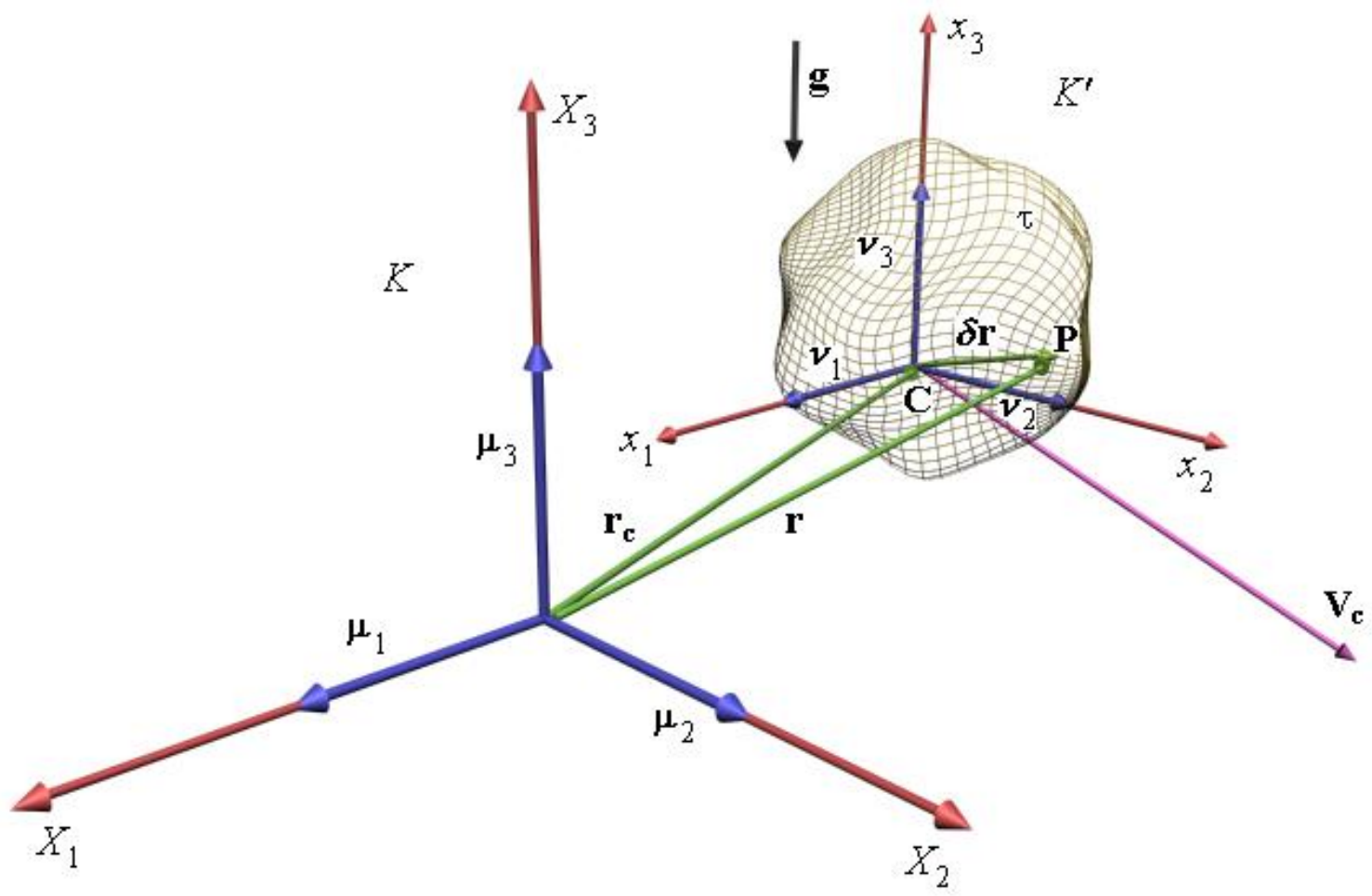

Figure 1: Cartesian coordinate system $K$ of a Galilean frame of reference and an individual finite continuum region $\tau$ subjected to the non-stationary Newtonian gravitation field, nonpotential terrestrial stress forces and non-stationary electromagnetic field

To solve the problem [8-12, 23, 25] of the geomagnetic reversals, we established the generalized differential formulation of the first law of thermodynamics [13, 17, 23]

$$
\mathrm{dU}_{\tau}+\mathrm{dK}_{\tau}+\mathrm{d} \pi_{\tau}+\mathrm{dE}_{\mathrm{e}, \mathrm{m}, \tau}=\delta \mathrm{Q}_{\mathrm{e}, \mathrm{m}}+\delta \mathrm{Q}+\delta \mathrm{A}_{\mathrm{np}, \partial \tau}+\delta \Phi_{\mathrm{e}, \mathrm{m}}+\mathrm{dG}
$$

extending the established generalized formulation (1) of the first law of thermodynamics by taking into account (along with the classical terms $\delta \mathrm{Q}$ and $\mathrm{dU}_{\tau}[22,24,26,27]$ and the established $[2-4,7,14-16]$ terms $\mathrm{dK}_{\tau}, \mathrm{d} \pi_{\tau}, \delta \mathrm{A}_{\mathrm{np}, \partial \tau}$ and $\left.\mathrm{dG}\right)$ the additional terms $[13,15,17$, 23]: the differential change $\mathrm{dE}_{\mathrm{e}, \mathrm{m}, \tau}$ of electromagnetic energy $\mathrm{E}_{\mathrm{e}, \mathrm{m}, \tau}$ inside the individual continuum region $\tau$ (considered in the Galilean frame of reference), the differential energy flux $\delta \Phi_{\mathrm{e}, \mathrm{m}}$ of the electromagnetic energy exchanged across the boundary surface $\partial \tau$ (of the 
individual continuum region $\tau$ ), and the differential heating $\delta \mathrm{Q}_{\mathrm{e}, \mathrm{m}}$ due to the differential work of electrodynamic forces and due to the dissipated electromagnetic waves.

Taking into account the general relation (2) (represented in the generalized differential formulations (1) and (5) of the first law of thermodynamics) for the infinitesimal gravitational energy influence $\mathrm{dG}$, we obtained $[16,23]$ the following relation for the combined differential cosmic non-stationary energy gravitational influence $\mathrm{dG}\left(\tau_{\mathrm{c}, \mathrm{r}}\right)$ (during the infinitesimal time interval dt) of the Solar System (the planets, the Moon and the Sun) on the internal rigid core $\tau_{\mathrm{c}, \mathrm{r}}$ of the Earth:

$$
\mathrm{dG}\left(\tau_{\mathrm{c}, \mathrm{r}}\right)=\mathrm{dt} \iiint_{\tau_{\mathrm{c}, \mathrm{r}}} \frac{\partial \psi_{\mathrm{comb}}}{\partial \mathrm{t}} \rho_{\mathrm{c}, \mathrm{r}} \mathrm{dV}
$$

where $\rho_{\mathrm{c}, \mathrm{r}}=12800 \mathrm{~kg} \cdot \mathrm{m}^{-3}$ [29] is the mass density of the internal rigid core $\tau_{\mathrm{c}, \mathrm{r}}$, $\partial \psi_{\text {comb }} / \partial \mathrm{t} \equiv \partial \psi_{\text {comb }}\left(\tau_{\mathrm{c}, \mathrm{r}}, \mathrm{t}\right) / \partial \mathrm{t}$ is the partial derivative (of the combined cosmic gravitational potential $\psi_{\text {comb }} \equiv \psi_{\text {comb }}\left(\tau_{\mathrm{c}, \mathrm{r}}, \mathrm{t}\right)$ in the internal rigid core $\tau_{\mathrm{c}, \mathrm{r}}$ of the Earth) approximated as follows $[15,16,23]$

$$
\psi_{\text {comb }}\left(\tau_{\mathrm{c}, \mathrm{r}}, \mathrm{t}\right)=\psi_{3 \text { MOON }}\left(\mathrm{C}_{3}, \mathrm{t}\right)+\sum_{\mathrm{i}=1, \mathrm{i} \neq 3}^{9} \psi_{3 \mathrm{i}}\left(\mathrm{C}_{3}, \mathrm{t}\right)+\sum_{\mathrm{j}=5}^{8} \psi_{3 \mathrm{j}}^{\mathrm{s}}\left(\mathrm{C}_{3}, \mathrm{t}\right) .
$$

Here $\psi_{3 \text { MOON }}\left(\mathrm{C}_{3}, \mathrm{t}\right)$ is the gravitational potential $[2,7,30]$ created by the Moon at the mass center $\mathrm{C}_{3}$ of the Earth; $\psi_{3 \mathrm{i}}\left(\mathrm{C}_{3}, \mathrm{t}\right)$ is the gravitational potential $[2,7,14,30]$ created by the planet $\tau_{\mathrm{i}}$ at the mass center $\mathrm{C}_{3}$ of the Earth; $\psi_{3 \mathrm{j}}^{\mathrm{S}}\left(\mathrm{C}_{3}, \mathrm{t}\right)$ is the gravitational potential $[15,16]$ created by the Sun (due to the outer large planet $\tau_{\mathrm{j}}$ ) at the mass center $\mathrm{C}_{3}$ of the Earth.

We established $[15,16,23,31]$ that the combined differential cosmic energy gravitational influence per unit time and per unit volume $\mathrm{dG}\left(\tau_{\mathrm{c}, \mathrm{r}}\right) /\left(\mathrm{dtV}\left(\tau_{\mathrm{c}, \mathrm{r}}\right)\right.$ ) (on the internal rigid core $\tau_{\mathrm{c}, \mathrm{r}}$ of the Earth) has the maximal absolute value for the internal rigid core $\tau_{\mathrm{c}, \mathrm{r}}$ of the Earth (from all interior of the Earth) since the mass density $\rho_{c, r}=12800 \mathrm{~kg} \cdot \mathrm{m}^{-3}$ [29] (of the internal rigid core $\tau_{\mathrm{c}, \mathrm{r}}$ ) has the maximal value and the partial derivative $\partial \psi_{\text {comb }} / \partial \mathrm{t}$ is nearly constant value in the Earth [7, 23, 30, 31]. Taking into account this fact, we concluded [16, 23, 31] about the maximal intensity of the thermohygrogravidynamic processes $[15,16,23,31]$ in the internal rigid core $\tau_{\mathrm{c}, \mathrm{r}}$ of the Earth (and in the boundary region $\tau_{\mathrm{rf}}$ between the internal rigid core $\tau_{\mathrm{c}, \mathrm{r}}$ and the fluid core $\tau_{\mathrm{c}, \mathrm{f}}$ of the Earth) with respect to others regions of the Earth.

Based on the generalized formulation (1) of the first law of thermodynamics (used for the internal rigid core $\tau_{\mathrm{c}, \mathrm{r}}$ of the Earth), we formulated [15, 16, 23, 31] the global prediction thermohydrogravidynamic principles determining the maximal temporal intensifications of the established $[15,16,23,31]$ thermohygrogravidynamic processes (in the internal rigid core $\tau_{\mathrm{c}, \mathrm{r}}$ 
and in the boundary region $\tau_{\mathrm{rf}}$ between the internal rigid core $\tau_{\mathrm{c}, \mathrm{r}}$ and the fluid core $\tau_{\mathrm{c}, \mathrm{f}}$ of the Earth considered as a whole) subjected to the combined cosmic energy gravitational influence of the planets of the Solar System, the Moon and the Sun (owing to the gravitational interaction of the Sun with the outer large planets). We concluded [15, 16, 23, 31] (based on the generalized formulation (1) of the first law of thermodynamics used for the internal rigid core $\tau_{c, r}$ of the Earth) that the maximal intensifications of the established thermohygrogravidynamic processes are related with the corresponding maximal intensifications of the global and regional natural (seismotectonic, volcanic, climatic and magnetic) processes of the Earth.

The rigorous global prediction thermohydrogravidynamic principles (determining the maximal temporal intensifications near the time moments $\mathrm{t}=\mathrm{t}^{*}\left(\tau_{\mathrm{c}, \mathrm{r}}\right)$ and $\mathrm{t}=\mathrm{t}_{*}\left(\tau_{\mathrm{c}, \mathrm{r}}\right)$, respectively, of the thermohydrogravidynamic processes in the internal rigid core $\tau_{\mathrm{c}, \mathrm{r}}$ and in the boundary region $\tau_{\mathrm{rf}}$ between the internal rigid core $\tau_{\mathrm{c}, \mathrm{r}}$ and the fluid core $\tau_{\mathrm{c}, \mathrm{f}}$ of the Earth) are formulated as follows $[15,16,23,31]$ :

$$
\Delta \mathrm{G}\left(\tau_{\mathrm{c}, \mathrm{r}}, \mathrm{t}^{*}\left(\tau_{\mathrm{c}, \mathrm{r}}\right)\right)=\max _{\mathrm{t}} \int_{\mathrm{t}_{0}}^{\mathrm{t}} \mathrm{dt} \mathrm{t}^{\prime} \iiint_{\tau_{\mathrm{c}, \mathrm{r}}} \frac{\partial \psi_{\text {comb }}}{\partial \mathrm{t}^{\prime}} \rho_{\mathrm{c}, \mathrm{r}} \mathrm{dV} \text { - local maximum for time moment } \mathrm{t}^{*}\left(\tau_{\mathrm{c}, \mathrm{r}}\right),
$$

and

$$
\Delta \mathrm{G}\left(\tau_{\mathrm{c}, \mathrm{r}}, \mathrm{t}_{*}\left(\tau_{\mathrm{c}, \mathrm{r}}\right)\right)=\min _{\mathrm{t}} \int_{\mathrm{t}_{0}}^{\mathrm{t}} \mathrm{dt} \mathrm{t}^{\prime} \iiint_{\tau_{\mathrm{c}, \mathrm{r}}} \frac{\partial \psi_{\text {comb }}}{\partial \mathrm{t}^{\prime}} \rho_{\mathrm{c}, \mathrm{r}} \mathrm{dV} \text { - local minimum for time moment } \mathrm{t}_{*}\left(\tau_{\mathrm{c}, \mathrm{r}}\right) .
$$

The global prediction thermohydrogravidynamic principles (8) and (9) define the maximal and minimal combined cosmic integral energy gravitational influences ((8) and (9), respectively, for the time moments $\mathrm{t}=\mathrm{t}^{*}\left(\tau_{\mathrm{c}, \mathrm{r}}\right)$ and $\mathrm{t}=\mathrm{t}_{*}\left(\tau_{\mathrm{c}, \mathrm{r}}\right)$ ) on the considered internal rigid core $\tau_{\mathrm{c}, \mathrm{r}}$ (of the Earth) subjected to the combined cosmic integral energy gravitational influence of the planets of the Solar System, the Moon and the Sun (owing to the gravitational interaction of the Sun with the outer large planets).

\section{Findings}

To predict in advance (on 31 August, 2016 [23, 31]) the forthcoming ranges (since 1 September, 2016) of the next active forthcoming intensifications of the global natural (seismotectonic, volcanic, climatic and magnetic) processes of the Earth in 2016, we used [23, 31] the established $[15,16]$ global prediction thermohydrogravidynamic principle (8) determining the maximal temporal intensification near the time moments $\mathrm{t}=\mathrm{t}^{*}\left(\tau_{\mathrm{c}, \mathrm{r}}\right)$ of the thermohydrogravidynamic processes $[15,16]$ in the internal rigid core $\tau_{\mathrm{c}, \mathrm{r}}$ and in the boundary region $\tau_{\mathrm{rf}}$ between the internal rigid core $\tau_{c, r}$ and the fluid core $\tau_{c, f}$ of the Earth. We used [23,31] the principle (8) to obtain (for the considered real planetary configurations of the Earth and the planets of the Solar System) the numerical time moment

$$
\mathrm{t}^{*}\left(\tau_{\mathrm{c}, \mathrm{r}}, 2016\right)=2016.7666
$$

corresponding to the maximal (in 2016) combined planetary and solar integral energy gravitational influence (8) on the internal rigid core $\tau_{c, r}$ of the Earth $\left(\tau_{3}\right)$. Based on the global 
prediction thermohydrogravidynamic principle (8) and considering the real planetary configurations of the Earth and the planets of the Solar System for 2016, we obtained (in advance [31]) the numerical time moment (related with the maximal combined planetary and solar integral energy gravitational influence (8) on the internal rigid core $\tau_{\mathrm{c}, \mathrm{r}}$ of the Earth in 2016) (10), which corresponds approximately to 6 October, 2016. Based on the global prediction thermohydrogravidynamic principle (8) used for the range $(2004 \div 2015)$, we calculated $[23,31]$ the dates $\mathrm{t}^{*}\left(\tau_{\mathrm{c}, \mathrm{r}},(2004+\mathrm{m})\right) \quad(\mathrm{m}=0,1, \ldots, 11)$ corresponding to the different local maxima (8) of the combined planetary and solar integral energy gravitational influences (for the real planetary configurations during the range $(2004 \div 2015)$ ) on the internal rigid core $\tau_{\mathrm{c}, \mathrm{r}}$ of the Earth.

Considering the range $(2004 \div 2015)$ and analyzing the previous strongest earthquakes (occurred near the calculated dates $\left.\mathrm{t}^{*}\left(\tau_{\mathrm{c}, \mathrm{r}},(2004+\mathrm{m})\right), \mathrm{m}=0,1, \ldots, 11\right)$, we calculated [23, 31] the probability

$$
\operatorname{Pr}\left\{\mathrm{t}_{\mathrm{e}, \max , 2016} \in(19 \text { September } \div 23 \text { October, 2016) }\}=0.416\right.
$$

of the forthcoming strongest earthquakes (and related [4, 7, 13-17, 25, 32] strongest volcanic, climatic and magnetic processes in 2016) near the calculated numerical time moment $\mathrm{t}^{*}\left(\tau_{\mathrm{c}, \mathrm{r}}, 2016\right)=2016.7666$ during the forthcoming range $[23,31]$ :

(19 September $\div 23$ October, 2016).

Considering the range $(2004 \div 2015)$ and analyzing the previous strongest earthquakes (occurred near the calculated dates $\left.\mathrm{t}^{*}\left(\tau_{\mathrm{c}, \mathrm{r}},(2004+\mathrm{m})\right), \mathrm{m}=0,1, \ldots, 11\right)$, we calculated [23, 31] the probability

$$
\operatorname{Pr}\left\{\mathrm{t}_{\mathrm{e}, \mathrm{max}, 2016} \in(1 \text { September } \div 10 \text { November, 2016) }\}=0.75\right.
$$

of the forthcoming strongest earthquakes (and related [4, 7, 13-17, 25, 32] strongest volcanic, climatic and magnetic processes of the Earth in 2016) near the calculated numerical time moment $\mathrm{t}^{*}\left(\tau_{\mathrm{c}, \mathrm{r}}, 2016\right)=2016.7666[23,31]$ during the forthcoming range $[23,31]$ :

$$
\text { (1 September } \div 10 \text { November, 2016). }
$$

Considering (on 7 November, 2016 [23]) the range $(2004 \div 2015)$ and analyzing (during the first correction of the article [23] published on 26 January, 2017) the previous strongest earthquakes (occurred near the calculated dates $\left.\mathrm{t}^{*}\left(\tau_{\mathrm{c}, \mathrm{r}},(2004+\mathrm{m})\right), \mathrm{m}=0,1, \ldots, 11\right)$, we calculated (on 7 November, 2016 [23]) the following probabilities [23]

$$
\begin{aligned}
& \operatorname{Pr}\left\{\mathrm{t}_{\mathrm{e}, \mathrm{max}, 2016} \in(10 \text { August } \div 30 \text { November, 2016) }\}=0.833,\right. \\
& \operatorname{Pr}\left\{\mathrm{t}_{\mathrm{e}, \mathrm{max}, 2016} \in(28 \text { June, 2016 } \div 13 \text { January, 2017) }\}=0.916,\right. \\
& \operatorname{Pr}\left\{\mathrm{t}_{\mathrm{e}, \mathrm{max}, 2016} \in(15 \text { June, 2016 } \div 26 \text { January, 2017) }\}=0.99\right.
\end{aligned}
$$

of the forthcoming strongest earthquakes (and related [4, 7, 13-17, 25, 32] strongest volcanic, climatic and magnetic processes in 2016 and in the beginning of 2017) near the numerical time moment $\mathrm{t}^{*}\left(\tau_{\mathrm{c}, \mathrm{r}}, 2016\right)=2016.7666[23,31]$ during the calculated (on 7 November, 2016 [23]) following ranges: 
(10 August $\div 30$ November, 2016),

(28 June, 2016 $\div 13$ January, 2017),

(15 June, $2016 \div 26$ January, 2017).

To predict in advance (on 10 April, 2017 [33]) the forthcoming ranges of the next active forthcoming intensifications of the global natural (seismotectonic, volcanic, climatic and magnetic) processes of the Earth in 2017 since 18 July, 2017 and before 26 February, 2018, we used the established $[15,16,23,31]$ global prediction thermohydrogravidynamic principle (8) determining the maximal temporal intensification near the time moment $\mathrm{t}=\mathrm{t}^{*}\left(\tau_{\mathrm{c}, \mathrm{r}}\right)$ of the thermohydrogravidynamic processes [16] in the internal rigid core $\tau_{\mathrm{c}, \mathrm{r}}$ and in the boundary region $\tau_{\mathrm{rf}}$ between the internal rigid core $\tau_{\mathrm{c}, \mathrm{r}}$ and the fluid core $\tau_{\mathrm{c}, \mathrm{f}}$ of the Earth. We used the principle (8) to obtain (for the considered real planetary configurations of the Earth and the planets of the Solar System) the numerical time moment $t^{*}\left(\tau_{c, r}, 2017\right)$ corresponding to the maximal (in 2017) combined planetary and solar integral energy gravitational influence (8) on the internal rigid core $\tau_{\mathrm{c}, \mathrm{r}}$ of the Earth $\left(\tau_{3}\right)$. Based on the global prediction thermohydrogravidynamic principle (8) and considering the real planetary configurations of the Earth and the planets of the Solar System for 2017, we obtained (on 10 April, 2017 [33]) the numerical time moment (related with the maximal (in 2017) combined planetary and solar integral energy gravitational influence (8) on the internal rigid core $\tau_{c, r}$ of the Earth):

$$
\mathrm{t}^{*}\left(\tau_{\mathrm{c}, \mathrm{r}}, 2017\right)=2017.85 \text {, }
$$

which corresponds approximately to 7 November, 2017. Based on the global prediction thermohydrogravidynamic principle (8) used for the range $(2004 \div 2016)$, we calculated [23, 31] the dates $\mathrm{t}^{*}\left(\tau_{\mathrm{c}, \mathrm{r}},(2004+\mathrm{m})\right)(\mathrm{m}=0,1, \ldots, 12)$ corresponding to the different local maxima (8) of the combined planetary and solar integral energy gravitational influences (for the real planetary configurations during the range $(2004 \div 2016))$ on the Earth.

Considering the range $(2004 \div 2016)$ and analyzing the previous strongest earthquakes (occurred near the calculated dates $\left.\mathrm{t}^{*}\left(\tau_{\mathrm{c}, \mathrm{r}},(2004+\mathrm{m})\right), \mathrm{m}=0,1, \ldots, 12\right)$, we calculated (on 10 April, 2017 [33]) the following probabilities

$\operatorname{Pr}\left\{\mathrm{t}_{\mathrm{e}, \max , 2017} \in(5\right.$ November $\div 9$ November, 2017) $\}=0.077$,

$\operatorname{Pr}\left\{\mathrm{t}_{\mathrm{e}, \max , 2017} \in(4\right.$ November $\div 10$ November, 2017) $\}=0.154$,

$\operatorname{Pr}\left\{\mathrm{t}_{\mathrm{e}, \max , 2017} \in(3\right.$ November $\div 11$ November, 2017) $\}=0.23$,

$\operatorname{Pr}\left\{\mathrm{t}_{\mathrm{e}, \mathrm{max}, 2017} \in(29\right.$ October $\div 17$ November, 2017) $\}=0.307$,

$\operatorname{Pr}\left\{\mathrm{t}_{\mathrm{e}, \max , 2017} \in(22\right.$ October $\div 23$ November, 2017) $\}=0.384$,

$\operatorname{Pr}\left\{\mathrm{t}_{\mathrm{e}, \max , 2017} \in(13\right.$ October $\div 1$ December, 2017) $\}=0.461$,

$\operatorname{Pr}\left\{\mathrm{t}_{\mathrm{e}, \max , 2017} \in(12\right.$ October $\div 2$ December, 2017) $\}=0.538$,

$\operatorname{Pr}\left\{\mathrm{t}_{\mathrm{e}, \max , 2017} \in(6\right.$ October $\div 8$ December, 2017) $\}=0.692$,

$\operatorname{Pr}\left\{\mathrm{t}_{\mathrm{e}, \max , 2017-2018} \in(12\right.$ September, 2017 $\div$ 1 January, 2018) $\}=0.769$, 


$$
\begin{aligned}
& \operatorname{Pr}\left\{\mathrm{t}_{\mathrm{e}, \max , 2017-2018} \in(1 \text { August, 2017 } \div \text { 12 February, 2018) }\}=0.846\right. \text {, } \\
& \operatorname{Pr}\left\{\mathrm{t}_{\mathrm{e}, \max , 2017-2018} \in(22 \text { July, 2017 } \div 22 \text { February, 2018) }\}=0.923\right. \text {, } \\
& \operatorname{Pr}\left\{\mathrm{t}_{\mathrm{e}, \max , 2017-2018} \in(18 \text { July, 2017 } \div 26 \text { February, 2018) }\}=0.99\right.
\end{aligned}
$$

of the forthcoming strongest earthquakes (and related [4, 7, 13-17, 25, 32] strongest volcanic, climatic and magnetic processes in 2017 since 18 July, 2017 and before 26 February, 2018) near the numerical time moment $\mathrm{t}^{*}\left(\tau_{\mathrm{c}, \mathrm{r}}, 2017\right)=2017.85$ corresponding approximately to 7 November, 2017) during the calculated (on 10 April, 2017 [33]) following ranges:

( 5 November $\div 9$ November, 2017),

(4 November $\div 10$ November, 2017),

(3 November $\div 11$ November, 2017),

(29 October $\div 17$ November, 2017),

(22 October $\div 23$ November, 2017),

(13 October $\div 1$ December, 2017),

(12 October $\div 2$ December, 2017),

(6 October $\div 8$ December, 2017),

(12 September, 2017 $\div 1$ January, 2018),

(1 August, 2017 $\div 12$ February, 2018),

(22 July, 2017 $\div 22$ February, 2018),

(18 July, 2017 $\div 26$ February, 2018).

It means that the dates $\mathrm{t}_{\mathrm{e}, \max , 2017}$ and $\mathrm{t}_{\mathrm{e}, \mathrm{max}, 2017-2018}$ of the forthcoming strongest earthquakes (and related [4, 7, 13-17, 25, 32] strongest volcanic, climatic and magnetic processes of the Earth determined by the maximal (in 2017) combined planetary and solar integral energy gravitational influence (8) on the internal rigid core $\tau_{\mathrm{c}, \mathrm{r}}$ of the Earth near the numerical time moment $\mathrm{t}^{*}\left(\tau_{\mathrm{c}, \mathrm{r}}, 2017\right)=2017.85$ corresponding approximately to 7 November, 2017) will occur in the ranges (34), (35), (36), (37), (38), (39), (40), (41), (42), (43), (44) and (45) characterized by the probabilities (22), (23), (24), (25), (26), (27), (28), (29), (30), (31), (32) and (33), correspondingly.

These ranges (34) - (45) and the corresponding probabilities (22) - (33) were founded exceptionally (by eliminating the analysis of the strongest global climatic activity of the Earth during the range $(2004 \div 2016)$ ) based on the combined analysis of the dates of the previous strongest earthquakes occurred during the range $(2004 \div 2016)$ near the calculated dates $\mathrm{t}^{*}\left(\tau_{\mathrm{c}, \mathrm{r}},(2004+\mathrm{m})\right) \quad(\mathrm{m}=0,1, \ldots, 12)$ corresponding to the different local maxima (8) of the combined planetary and solar integral energy gravitational influences (related with the real planetary configurations during the range $(2004 \div 2017))$ on the internal rigid core $\tau_{c, r}$ of the Earth $\tau_{3}$ and on the Earth $\tau_{3}$ as a whole. 


\section{Discussions}

Let us discuss (in the beginning) the confirmed validity of the prediction (given by the calculated [23, 31] probabilities (11), (13), (15), (16) and (17)) of the thermohydrogravidynamic theory (based on the established $[15,16]$ global prediction thermohydrogravidynamic principle (8)) concerning the strongest intensifications of the global natural processes of the Earth in 2016 since 1 September, 2016 and before 26 January, 2017. Considering the Fig. 2 (demonstrating the magnitudes $M$ and the dates (in yr) of the significant earthquakes (before 9 December, 2016) according to the U.S. Geological Survey) in 2016, we saw (on 18 December, 2016, during the second correction of the article [23]) that the predicted (in advance, on 7 November, 2016 during the first correction of the article [23]) range (10 August $\div 30$ November, 2016) (of the probable strongest intensifications of the global seismotectonic and climatic processes of the Earth in 2016 since 1 September, 2016) contains the date (13 November, 2016 marked by symbol B on Fig. 2) of the strongest 7.8-magnitude (according to the U.S. Geological Survey) earthquake, which struck central New Zealand (near the city of Christchurch in the South Island) confirming the validity of the predicted range (10 August $\div 30$ November, 2016) of the probable strongest intensifications (characterized by the corresponding probability $\operatorname{Pr}=0.833$ ) of the global seismotectonic and climatic processes of the Earth in 2016 since 1 September, 2016.

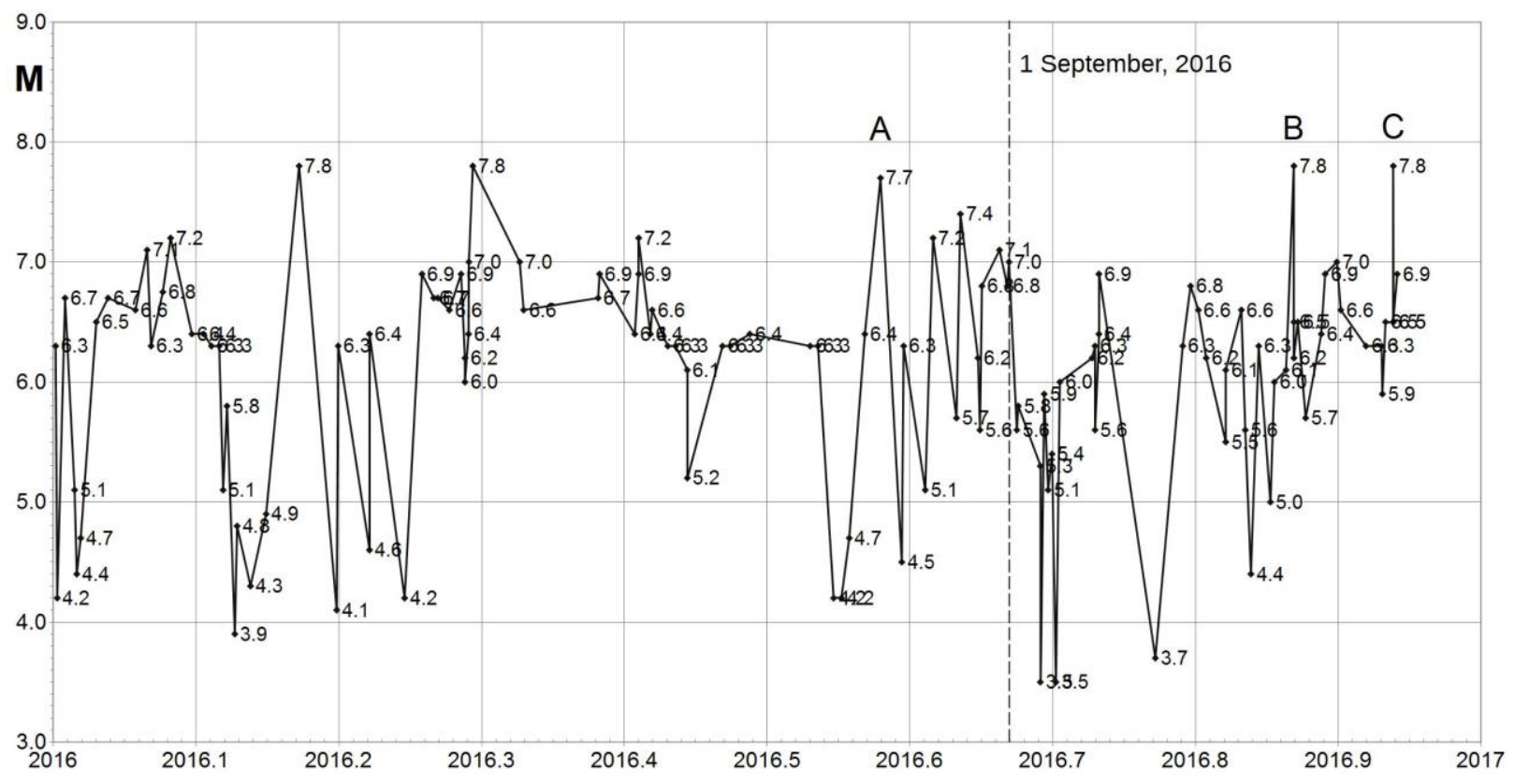

Figure 2: The magnitudes $\mathrm{M}$ and the dates (in yr) of the significant earthquakes (according to the U.S. Geological Survey) in 2016 before 9 December, 2016 [23]

We saw (on 18 December, 2016, during the second correction of the article [23]) that the predicted (in advance, on 7 November, 2016 during the first correction of the article [23]) range (28 June, 2016 $\div 13$ January, 2017) (of the probable strongest intensifications of the global seismotectonic and climatic processes of the Earth in 2016 since 1 September, 2016) contains (along with the strongest 7.8-magnitude earthquake occurred on 13 November, 2016) the date (8 
December, 2016 marked by symbol C on Fig. 2) of the strongest 7.8-magnitude (according to the U.S. Geological Survey) earthquake, which struck near the Solomon Islands confirming the validity of the predicted range (28 June, 2016 $\div 13$ January, 2017) of the probable strongest intensifications (characterized by the corresponding probability $\operatorname{Pr}=0.916$ ) of the global seismotectonic and climatic processes of the Earth in 2016 since 1 September, 2016. We saw (on 18 December, 2016, during the second correction of the article [23]) also that the predicted range (28 June, 2016 $\div 13$ January, 2017) contains the date (29 July, 2016 marked by symbol A on Fig. 2) of the strongest 7.7-magnitude (according to the U.S. Geological Survey) earthquake occurred before 1 September, 2016.

Analyzing (on 7 November, 2016, during the first correction of the article [23]) the climatic activity of the Earth in 2016, we concluded [23] that Hurricane Matthew produced the strongest devastating climatic (meteorological) activity during the predicted (in advance [31], on 31 August, 2016) range (19 September $\div 23$ October, 2016) of the probable strongest (in 2016 since 1 September, 2016) intensification (characterized by the probability $\operatorname{Pr}=0.416$ ) of the global climatic (meteorological) activity of the Earth in 2016. According to the U.S. National Hurricane Center, Matthew was (on 30 September, 2016) the most powerful devastating hurricane in the Atlantic since the last Category 5 hurricane Felix observed in the Atlantic on September 2007. According to the U.S. National Hurricane Center, "Matthew's top sustained winds have risen from $115 \mathrm{mph}(185 \mathrm{kph})$ to $125 \mathrm{mph}(205 \mathrm{mph})$ in just a few hours early Thursday (on 6 October, 2016) as the storm continues to batter the central Bahamas" [34].

We pointed out [23] the first unquestionable fact that the date of 6 October, 2016 (when "Hurricane Matthew has gained new muscle over the Bahamas" [34]) is in the perfect agreement with the calculated (in advance [31], on 31 August, 2016) numerical time moment $\mathrm{t}^{*}\left(\tau_{\mathrm{c}, \mathrm{r}}, 2016\right)=2016.7666$ (corresponding approximately to 6 October, 2016) of the maximal (in 2016) combined planetary and solar integral energy gravitational influence (8) on the internal rigid core $\tau_{c, r}$ of the Earth (and on the Earth as a whole). We pointed out [23] that the probability of this perfect agreement (considered as casual coincidence) is approximated by the obvious numerical value $(1 / 365) \cdot(1 / 365)$, which is very small number confirming that this perfect agreement is not a casual coincidence. We concluded [23] that this perfect agreement may be considered as the convincing evidence of the validity of the established $[15,16,31]$ global prediction thermohydrogravidynamic principle (8) concerning the maximal intensifications of the global and regional climatic activities of the Earth. We concluded [23] that this perfect agreement may be considered also as the convincing evidence of the cosmic (combined planetary and solar) energy gravitational genesis of the global and regional climatic (meteorological) activities of the Earth related with strong hurricanes.

We pointed out [23] the second unquestionable fact that the strongest (in 2016 since 1 September and before 7 November, 2016) climatic (meteorological) activity of the Earth (related with hurricane Matthew) corresponds perfectly to the predicted (in advance [31], on 31 August, 2016) range (19 September $\div 23$ October, 2016) (based on the analysis of the previous strongest earthquakes during the range $(2004 \div 2015)$ ) of the of probable strongest (in 2016 since 1 September, 2016) intensification (characterized by the probability $\operatorname{Pr}=0.416$ ) of the global climatic (meteorological) activity of the Earth. We considered [23] this second unquestionable 
fact as the convincing evidence of the Gutenberg's [35] idea that the seismic activity of the Earth is closely related with the climatic (meteorological) activity of the Earth.

We pointed out [23] the third unquestionable fact (which confirms the Gutenberg's [35] idea about the global seismic-climatic relation) that the powerful 6.5-magnitude (according to the Japan Meteorological Agency) earthquake (occurred on 23 September, 2016 southeast of Tokyo) and the powerful 6.6-magnitude earthquake (occurred on 21 October, 2016 in Tottori, a prefecture in western Japan about 430 miles west of Tokyo) were realized during the predicted (in advance [31], on 31 August, 2016) range (19 September $\div 23$ October, 2016) of the probable strongest intensifications (characterized by the corresponding probability $\operatorname{Pr}=0.416$ ) of the global seismotectonic and climatic processes of the Earth in 2016 since 1 September, 2016.

We pointed out [23] the fourth unquestionable fact that the powerful 6.6-magnitude (according to the U.S. Geological Survey) earthquake (which is the strongest Italian devastating earthquake in nearly 40 years) rocked central Italy (near the Umbrian town of Norcia) on 30 October, 2016 confirming the validity of the predicted (in advance [31], on 31 August, 2016) range (1 September $\div 10$ November, 2016) of the probable strongest intensifications (characterized by the corresponding probability $\operatorname{Pr}=0.75$ ) of the global seismotectonic and climatic processes of the Earth in 2016 since 1 September, 2016.

Analyzing (on 18 December, 2016, during the second correction of the article [23]) the seismotectonic activity of the Earth in 2016 since 1 September, 2016 (by considering the significant earthquakes according to the U.S. Geological Survey), we pointed out [23] the fifth unquestionable fact that the powerful 7.8-magnitude (according to the U.S. Geological Survey) earthquake struck central New Zealand (near the city of Christchurch in the South Island) on 13 November, 2016 confirming the validity of the predicted (in advance, on 7 November, 2016 during the first correction of the article [23]) range (10 August $\div 30$ November, 2016) of the probable strongest intensifications (characterized by the corresponding probability $\operatorname{Pr}=0.833$ ) of the global seismotectonic and climatic processes of the Earth in 2016 since 1 September, 2016. We pointed out [23] that the date (13 November, 2016) of the powerful 7.8-magnitude earthquake occurred near the Full Moon (on 14 November, 2016) confirming the validity of the established $[15,36]$ significance of the Moon as the predominant cosmic trigger mechanism of the prepared earthquakes.

Analyzing (on 18 December, 2016, during the second correction of the article [23]) the seismotectonic activity of the Earth in 2016 since 1 September, 2016 (by considering the significant earthquakes according to the U.S. Geological Survey), we pointed out [23] the sixth unquestionable fact that the powerful 7.8-magnitude (according to the U.S. Geological Survey) earthquake struck near the Solomon Islands on 8 December, 2016 confirming the validity of the predicted (in advance, on 7 November, 2016 during the first correction of the article [23]) range (28 June, 2016 $\div 13$ January, 2017) of the probable strongest intensifications (characterized by the corresponding probability $\mathrm{Pr}=0.916)$ of the global seismotectonic and climatic processes of the Earth in 2016 since 1 September, 2016. We pointed out [23] (on 18 December, 2016 [23]) that the strongest 7.8-magnitude (according to the U.S. Geological Survey) earthquakes (occurred on 13 November, 2016 and on 8 December, 2016) confirmed the validity of the established $[15,16]$ global prediction thermohydrogravidynamic principle (8) concerning the 
strongest intensification of the global seismotectonic processes of the Earth (in 2016 since 1 September, 2016) during the predicted (in advance, during the first correction of the article [23] on 7 November, 2016) ranges (10 August $\div 30$ November, 2016) and (28 June, 2016 $\div 13$ January, 2017) of the strongest intensifications (characterized by the corresponding probabilities $\operatorname{Pr}=0.833$ and $\operatorname{Pr}=0.916$, respectively) of the global seismotectonic and climatic processes of the Earth in 2016 since 1 September, 2016. The article [23] was published on 26 January, 2017, i.e. in the date of the end of the predicted range (20).

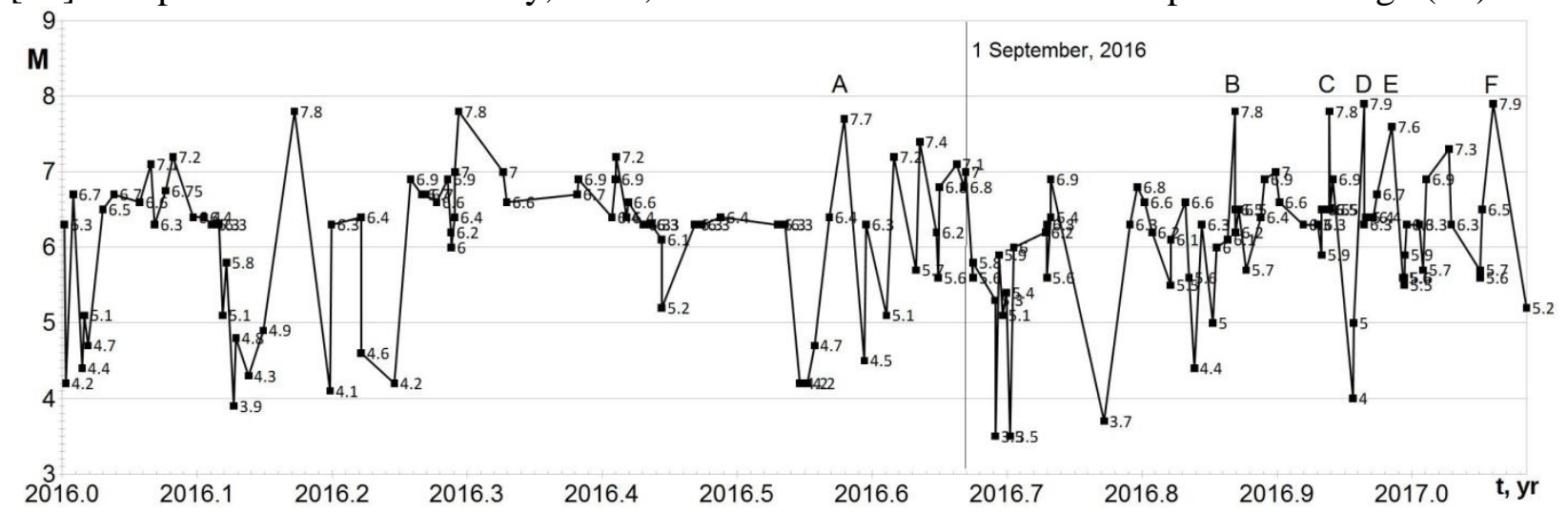

Figure 3: The magnitudes $\mathrm{M}$ and the dates (in $\mathrm{yr}$ ) of the significant earthquakes (according to the U.S. Geological Survey) in 2016 and before 31 January, 2017

Fig. 3 shows the magnitudes $M$ and the dates (in yr) of the significant earthquakes (according to the U.S. Geological Survey) in 2016 and before 31 January, 2017. Analyzing (on 10 April, 2017) the seismotectonic activity of the Earth in 2016 since 9 December, 2016 (in addition to the made analysis [23]) and before 13 January, 2017 (by considering the significant earthquakes according to the U.S. Geological Survey), we have the seventh and eighth additional unquestionable facts (in addition to the considered facts [23]) that the powerful 7.9-magnitude (according to the U.S. Geological Survey) earthquake (marked by symbol D on Fig. 3) struck the Papua New Guinea on 17 December, 2016 and the powerful 7.6-magnitude (according to the U.S. Geological Survey) earthquake (marked by symbol E on Fig. 3) struck the Chile on 25 December, 2016 confirming the validity of the predicted (in advance, on 7 November, 2016 during the first correction of the article [23]) range (28 June, 2016 $\div 13$ January, 2017) of the probable strongest intensifications (characterized by the corresponding probability $\operatorname{Pr}=0.916$ ) of the global seismotectonic and climatic processes of the Earth in 2016 since 28 June, 2016 and before 13 January, 2017. Analyzing (on 10 April, 2017) the significant earthquakes of the Earth in 2016 (according to the U.S. Geological Survey) since 9 December, 2016 and before 26 January, 2017 (which is the date of the publication [23]), we have the ninth additional unquestionable fact that the powerful 7.9-magnitude (according to the U.S. Geological Survey) earthquake (marked by symbol F on Fig. 3) struck the Papua New Guinea on 22 January, 2017 confirming the validity of the predicted (in advance, on 7 November, 2016 during the first correction of the article [23]) range (15 June, 2016 $\div 26$ January, 2017) of the probable strongest intensifications (characterized by the corresponding probability $\operatorname{Pr}=0.99$ ) of the global seismotectonic and climatic processes of the Earth in 2016 since 15 June, 2016 and before 26 January, 2017. Analyzing (on 10 April, 2017) the seismotectonic activity of the Earth in 2017 since 31 January, 2017 and before 10 April, 2017 (by considering the significant earthquakes according to the U.S. Geological Survey), we have the tenth additional unquestionable fact of the absence of the strong 
earthquakes (characterized by the magnitudes $M \geq 7.0$ ) in the range from 31 January, 2017 to 10 April, 2017.

We can discuss (on 31 August, 2017 during the date of the second submission of the corrected article for publication to the International Journal of Research - GRANTHAALAYAH) the confirmed validity of the prediction (made on 10 April, 2017 [33]) given by the calculated probabilities (33), (32) and (31)) of the thermohydrogravidynamic theory (based on the established [15, 16] global prediction thermohydrogravidynamic principle (8)) concerning the strongest intensifications of the global natural (seismotectonic, volcanic and climatic) processes of the Earth since 18 July, 2017 and before 26 February, 2018. Considering (on 31 August, 2017) the significant earthquakes (according to the U.S. Geological Survey) in 2017 before 31 August, 2017, we have the unquestionable fact that the date (17 July, 2017, 23:34:13 UTC) of the strongest 7.8-magnitude (strongest in 2017 before 31 August, 2017 according to the U.S. Geological Survey) earthquake (which struck Russia's Kamchatka Peninsula 198 km ESE of Nikol'skoye according to the U.S. Geological Survey) belongs practically (with the error of 26 minutes) to the predicted (on 10 April, 2017 [33]) range (45) characterized by the probability (33). We have the unquestionable fact that "on Wednesday, the University of Utah Seismograph Stations (UUSS) had recorded 1,284 events, the largest being magnitude 4.4" ([37] published on July 20, 2017), that is the period of the Yellowstone supervolcano intensification (on Wednesday, July 19, 2017) belongs to the predicted (on 10 April, 2017 [33]) range (45) characterized by the probability (33). We have the unquestionable fact that "the flooding has paralysed Gujarat" ([38] published on July 31, 2017), that is the period of the Indian severe monsoon floods (especially in Gujarat) belongs to the predicted (on 10 April, 2017 [33]) range (44) characterized by the probability (32). We have the unquestionable fact that "typhoon Noru dumped heavy rain on Japan Tuesday as it moved back out to sea, causing flooding and property damage while the number of injured reportedly rose to 51" ([39] published on August 8, 2017), that is the period of the typhoon Noru belongs to the predicted (on 10 April, 2017 [33]) range (43) characterized by the probability (31). We have the unquestionable fact that "more than 800 people have been killed and 24 million affected following widespread floods across south Asia" ([40] published on August 22, 2017), that is the period of the widespread floods across south Asia belongs to the predicted (on 10 April, 2017 [33]) range (43) characterized by the probability (31). We have the unquestionable fact that "damaging hurricane Harvey settles in over southeast Texas" ([41] published on August 27, 2017), that is the period of the damaging hurricane Harvey belongs to the predicted (on 10 April, 2017 [33]) range (43) characterized by the probability (31).

\section{Conclusions}

We have presented in Section 2 (Methodology) the established [2-4, 7, 13-17, 21, 23, 25, 30-32, 36] generalized formulations (1) and (5) of the first law of thermodynamics and the established $[15,16,23,31]$ global prediction thermohydrogravidynamic principles (8) and (9) (of the cosmic seismology $[15,16,23,31])$ determining the maximal temporal intensifications of the global and regional natural (sesmotectonic, volcanic, climatic and magnetic) processes of the Earth. The generalization (1) of the first law of thermodynamics [2-4, 7, 13-17, 21, 23, 25, 31-32] is founded for the individual finite continuum region $\tau$ (considered in the Galilean frame of reference) subjected to the cosmic and terrestrial non-stationary Newtonian gravitational field and non-potential terrestrial stress forces characterized by the symmetric stress tensor $\mathbf{T}$ [22]. 
The expanded [13, 17] generalized formulation (5) of the first law of thermodynamics is founded for the individual finite continuum region $\tau$ (considered in the Galilean frame of reference) subjected to the cosmic and terrestrial non-stationary Newtonian gravitational field, non-potential terrestrial stress forces and non-stationary electromagnetic field. The established $[15,16,23,31]$ global prediction thermohydrogravidynamic principles (8) and (9) (determining (in the frame of the cosmic seismology $[15,16,23,31])$ the maximal temporal intensifications of the global natural (seismotectonic, volcanic, climatic and magnetic) processes of the Earth) are founded for the considered internal rigid core $\tau_{\mathrm{c}, \mathrm{r}}$ of the Earth subjected to the combined integral energy gravitational influence of the planets (Mercury, Venus, Mars and Jupiter), the Moon and the Sun due to the gravitational interactions of the Sun with Jupiter Saturn, Uranus and Neptune.

We have considered in Section 3 (Findings) the maximal combined planetary and solar integral energy gravitational influences $\left((8)\right.$ for the time moments $\mathrm{t}^{*}\left(\tau_{\mathrm{c}, \mathrm{r}}, 2016\right)=2016.7666$ and $\mathrm{t}^{*}\left(\tau_{\mathrm{c}, \mathrm{r}}, 2017\right)=2017.85$, respectively) on the considered internal rigid core $\tau_{\mathrm{c}, \mathrm{r}}$ of the Earth for 2016 and 2017, respectively. We have presented in Section 3 (Findings) the prognostication [23, 31] based on the global prediction thermohydrogravidynamic principle (8) (of the thermohydrogravidynamic theory $[2-4,7,13-17,21,23,25,30-32,36])$ concerning the strongest intensifications of the global natural (sesmotectonic and climatic) processes of the Earth in 2016 (since 1 September, 2016 and before 26 January, 2017) near the calculated (in advance [31], on 31 August, 2016) numerical time moment $\mathrm{t}^{*}\left(\tau_{\mathrm{c}, \mathrm{r}}, 2016\right)=2016.7666$ corresponding approximately to 6 October, 2016. We have presented (on 21 August, 2017) in Section 3 (Findings) the prognostication deductions (made on 10 April, 2017 [33]) based on the global prediction thermohydrogravidynamic principle (8) concerning the strongest intensifications of the global natural (sesmotectonic, volcanic, climatic and magnetic) processes of the Earth determined by the maximal (for the time moment $\mathrm{t}^{*}\left(\tau_{\mathrm{c}, \mathrm{r}}, 2017\right)=2017.85$, which corresponds approximately to 7 November, 2017) combined planetary and solar integral energy gravitational influences on the internal rigid core $\tau_{\mathrm{c}, \mathrm{r}}$ of the Earth. The numerical time moment $\mathrm{t}^{*}\left(\tau_{\mathrm{c}, \mathrm{r}}, 2017\right)=2017.85$ (corresponding approximately to 7 November, 2017) is obtained based on the established $[15,16,23,31]$ global prediction thermohydrogravidynamic principle (8) used for the real planetary configurations of the Earth and the planets of the Solar System. The founded numerical time moment $\mathrm{t}^{*}\left(\tau_{\mathrm{c}, \mathrm{r}}, 2017\right)=2017.85$ is related with the maximal (for 2017) combined planetary and solar integral energy gravitational influence (8) on the internal rigid core $\tau_{\mathrm{c}, \mathrm{r}}$ of the Earth and on the Earth as a whole. We have presented Section 3 (Findings) the founded (on 10 April, 2017 [33]) ranges (34), (35), (36), (37), (38), (39), (40), (41), (42), (43), (44) and (45) of the dates $t_{e, \max , 2017}$ and $t_{e, \max , 2017-2018}$ of the forthcoming strongest earthquakes (and related [4, 7, 13-17, 25, 32] strongest volcanic, climatic and magnetic processes of the Earth determined by the maximal (in 2017) combined planetary and solar integral energy gravitational influence (8) on the internal rigid core $\tau_{\mathrm{c}, \mathrm{r}}$ of the Earth near the numerical time moment $\mathrm{t}^{*}\left(\tau_{\mathrm{c}, \mathrm{r}}, 2017\right)=2017.85$ corresponding approximately to 7 November, 2017) characterized by 
the probabilities (22), (23), (24), (25), (26), (27), (28), (29), (30), (31), (32) and (33), correspondingly.

We have presented in Section 4 (Discussions) the confirmed [23] validity of the prognostication $[23,31]$ based on the global prediction thermohydrogravidynamic principle (8) (of the thermohydrogravidynamic theory $[2-4,7,13-17,21,23,25,30-32,36]$ ) concerning the strongest intensifications of the global natural (sesmotectonic and climatic) processes of the Earth in 2016 (since 1 September, 2016 and before 26 January, 2017) near the calculated (in advance [31], on 31 August, 2016) numerical time moment $\mathrm{t}^{*}\left(\tau_{\mathrm{c}, \mathrm{r}}, 2016\right)=2016.7666$ corresponding approximately to 6 October, 2016.

Considering (on 31 August, 2017) the significant earthquakes (according to the U.S. Geological Survey) in 2017 before 31 August, 2017, we have established the unquestionable fact that the date (17 July, 2017, 23:34:13 UTC) of the strongest 7.8-magnitude (strongest in 2017 before 31 August, 2017 according to the U.S. Geological Survey) earthquake (which struck Russia's Kamchatka Peninsula) belongs practically (with the error of 26 minutes) to the predicted (on 10 April, 2017 [33]) range (45) characterized by the probability (33). We have presented the evidence [37] (published on July 20, 2017) that "on Wednesday, the University of Utah Seismograph Stations (UUSS) had recorded 1,284 events, the largest being magnitude 4.4", that is the period of the Yellowstone supervolcano intensification (on Wednesday, July 19, 2017) belongs to the predicted (on 10 April, 2017 [33]) range (45) characterized by the probability (33). We have presented the evidence [38] (published on July 31, 2017) that "the flooding has paralysed Gujarat" [38], that is the period of the Indian severe monsoon floods (especially in Gujarat) belongs to the predicted (on 10 April, 2017 [33]) range (44) characterized by the probability (32). We have presented the evidence [39] (published on August 8, 2017) that "typhoon Noru dumped heavy rain on Japan Tuesday as it moved back out to sea, causing flooding and property damage while the number of injured reportedly rose to 51" [39], that is the period of the typhoon Noru belongs to the predicted (on 10 April, 2017 [33]) range (43) characterized by the probability (31). We have presented the evidence [40] (published on August $22,2017)$ that "more than 800 people have been killed and 24 million affected following widespread floods across south Asia" [40], that is the period of the widespread floods across south Asia belongs to the predicted (on 10 April, 2017 [33]) range (43) characterized by the probability (31). We have presented the evidence [41] (published on August 27, 2017) that "damaging hurricane Harvey settles in over southeast Texas" [41], that is the period of the damaging hurricane Harvey belongs to the predicted (on 10 April, 2017 [33]) range (43) characterized by the probability (31). The considered above facts and evidences confirm the validity of the established $[15,16,31]$ global prediction thermohydrogravidynamic principle (8) (of the thermohydrogravidynamic theory [2-4, 7, 13-17, 21, 23, 25, 30-32, 36]) concerning the second subrange of the strongest (in 2017) intensifications of the global natural (seismotectonic, volcanic and climatic) processes of the Earth since 18 July, 2017 and before 26 February, 2018 [33]. The author suggests the reasonable applications of the published findings (that is the founded forthcoming ranges (34), (35), (36), (37), (38), (39), (40), (41) and (42) characterized by the probabilities (22), (23), (24), (25), (26), (27), (28), (29) and (30), correspondingly, of the strongest intensifications of the global natural processes of the Earth) for the governments of the world-wide states to diminish (in advance) the devastating effects of the forthcoming natural catastrophic processes of the Earth. 


\section{Acknowledgements}

The author thanks the Editor with gratitude for the editorial comments and corrections improving the final text of the article. The author thanks Mr. A.G. Starikov, Mr. P.E. Shsherbinin and Mrs. O.A. Pavlova for the very constructive discussions.

\section{References}

[1] Charles Francis Richter. (1958). "Elementary Seismology." San Francisco, USA: W.H. Freeman.

[2] Sergey Victorovich Simonenko. (2013). "Fundamentals Of The Thermohydrogravidynamic Theory Of The Global Seismotectonic Activity Of The Earth." International Journal of Geophysics, 2013 (519829), 1-39. http://dx.doi.org/10.1155/2013/519829.

[3] Sergey Victorovich Simonenko. (2014). "The Practical Forecasting Aspects Of The Thermohydrogravidynamic Theory Of The Global Seismotectonic Activity Of The Earth Concerning To The Japanese Earthquakes Near The Tokyo Region." American Journal of Earth Sciences, 1(2), 38-61.

http://www.openscienceonline.com/journal/archive2?journalId=715\&paperId=457.

[4] Sergey Victorovich Simonenko. (2014). "The Linkage Of The Different Distinct Great Volcanic Eruptions Of The Thera (Santorini) In The Range $(1700 \div 1450 \pm 14)$ BC And The Related Subsequent Intensifications Of The Global Seismicity And Volcanic Activity In The End Of The 19th Century And In The Beginning Of The 20th Century, In The End Of The 20th Century, And In The Beginning Of The 21 st Century AD.” Journal of Advances in Physics, 4(2), 484-516. http://cirworld.org/journals/index.php/jap/article/view/53N.

[5] T. Simkin, L. Siebert, L. McClelland, D. Bridge, C. Newhall, and J. Latter. (1981). "Volcanoes Of The World." Stroudsburg: Hutchinson Ross.

[6] Hubert Horace Lamb. (1977). "Climate: Present, Past And Future. Vol. 2: Climatic History And The Future." London, UK: Methuen.

[7] Sergey Victorovich Simonenko. (2009). "Fundamentals Of The Thermohydrogravidynamic Theory Of Cosmic Genesis Of The Planetary Cataclysms." Nakhodka, Russia: Institute of Technology and Business Press.

[8] V. Bucha. (1967). "Archaeomagnetic And Palaeomagnetic Study Of The Magnetic Field Of The Earth In The Past 600000 Years.” Nature, 213(5080), 1005-1007.

[9] I. K. Crain, P. L. Crain, and M. G. Plaut. (1969). "Long Period Fourier Spectrum Of Geomagnetic Reversals." Nature, 223(5203), 283-283.

[10] Nils-Axel Mörner, J. P. Lanser, and J. Hospers. (1971). "Late Weichselian Palaeomagnetic Reversal.” Nature. Physical Science, 234, 173-174.

[11] M. Barbetti, and M. McElhinny. (1972). "Evidence Of A Geomagnetic Excursion 30000 Yr BP." Nature, 239(5371), 327-330.

[12] Reidar Løvlie. (1989). "Palaeomagnetic Excursions During The Last Interglacial/ Glacial Cycle: A Synthesis.” Quaternary International, 3-4, 5-11. https://doi.org/10.1016/1040-6182(89)900682.

[13] Sergey Victorovich Simonenko. (2014). "The Evidence Of The Cosmic Energy Gravitational Genesis Of The Forthcoming Intensification Of The Global Seismotectonic, Volcanic, Climatic And Magnetic Activity Of The Earth, And The Problem Of The Controlled Thermonuclear Reactions." International Journal of Latest Research in Science and Technology, 3(3), 206-214.

[14] Sergey Victorovich Simonenko. (2007). "Thermohydrogravidynamics Of The Solar System." Nakhodka, Russia: Institute of Technology and Business Press.

[15] Sergey Victorovich Simonenko. (2012). "The Cosmic Energy Gravitational Genesis Of The Increase Of The Seismic And Volcanic Activity Of The Earth In The Beginning Of The $21^{\text {st }}$ Century AD.” Nakhodka, Russia: Institute of Technology and Business Press. 
[16] Sergey Victorovich Simonenko. (2014). “The Prognosticating Aspects Of The Developed Cosmic Geophysics Concerning The Subsequent Forthcoming Intensifications Of The Global Seismicity, Volcanic And Climatic Activity Of The Earth In The $21^{\text {st }}$ Century." British Journal of Applied Science \& Technology, 4(25), 3563-3630. http://sciencedomain.org/download/NTE2NEBAcGY.

[17] Sergey Victorovich Simonenko. (2014). "The Evidence Of The Cosmic Energy Gravitational Genesis Of The Possible Forthcoming Geomagnetic Reversal Of The Magnetic Field Of The Earth.” International Journal of Engineering Science and Innovative Technology, 3(6), 568-585. http://www.ijesit.com/archive/19/volume-3issue-6november-2014.html.

[18] David J. Rose. (1971). “Controlled Nuclear Fusion: Status And Outlook.” Science, 172 (3985): 797-808.

[19] Pyotr Leonidovich Kapitza. (1978). "Plasma And The Controlled Thermonuclear Reaction. Nobel Lecture In Physics." Moscow, USSR: Institute for Physical problems of the USSR Academy of Sciences.

[20] "Progress In Fusion." (2014). ITER Organization.

[21] Sergey Victorovich Simonenko. (2006). "Non-equilibrium Statistical Thermohydrodynamics of Turbulence." Moscow, Russia: Nauka.

[22] Istvan Gyarmati. (1970). "Non-equilibrium Thermodynamics. Field Theory And Variational Principles." Berlin, Germany: Springer-Verlag.

[23] Sergey Victorovich Simonenko. (2016). "The Confirmed Validity Of The Thermohydrogravidynamic Theory Concerning The Strongest Intensifications Of The Global Natural Processes Of The Earth In 2016 Since 1 September, 2016." British Journal of Applied Science \& Technology, 18(5), 1-20. Article no.BJAST.30049. http://www.journalrepository.org/media/journals/BJAST_5/2017/Jan/Simonenko1852016BJAST 30049.pdf.

[24] Sybren Ruurds de Groot and Peter Mazur. (1962). "Non-equilibrium Thermodynamics." Amsterdam, Holland: North-Holland Publishing Company.

[25] Sergey Victorovich Simonenko. (2015). "The Cosmic Energy Gravitational Genesis Of The Forthcoming Intensifications Of The Global Seismotectonic, Volcanic, Climatic And Magnetic Activities Since 2016 AD.” American Journal of Earth Sciences. 2(6), 211-229. http://www.openscienceonline.com/journal/archive2?journalId=715\&paperId=2661.

[26] Josiah Willard Gibbs. (1873). "Graphical Methods In The Thermodynamics Of Fluids." Transactions of the Connecticut Academy, 2, 309-342.

[27] Lev Davidovich Landau, and Evgeny Mikhailovich Lifshitz. (1976). "Theoretical Physics. Vol. 5. Statistical Physics.” Moscow, Russia: Nauka. In Russian.

[28] Sergey Victorovich Simonenko. (2004). "The Macroscopic Non-equilibrium Kinetic Energies Of A Small Fluid Particle." Journal of Non-Equilibrium Thermodynamics, 29 (2), 107-123.

[29] T. Alboussière, R. Deguen, and M. Melzani. (2010). "Melting-induced Stratification Above The Earth's Inner Core Due To Convective Translation." Nature, 466, 744-747.

[30] Sergey Victorovich Simonenko. (2010). "Fundamentals Of The Thermohydrogravidynamic Theory Of Cosmic Genesis Of The Planetary Cataclysms." Second Edition. Nakhodka, Russia: Institute of Technology and Business Press.

[31] Sergey Victorovich Simonenko. (2016). "The Prognosticating Results Of The Cosmic Seismology Concerning The Forthcoming Intensification Of The Global Seismotectonic, Volcanic And Climatic Activities Of The Earth From 1 September To 10 November, 2016 AD." Journal of Advances in Environmental Sciences, 1(2), 90-101. https://cirworld.com/index.php/jes/article/view/4261.

[32] Sergey Victorovich Simonenko. (2014). "Fundamentals Of The Non-equilibrium Statistical Thermohydrodynamic Theory Of The Small-scale Dissipative Turbulence And The Deterministic Thermohydrogravidynamic Theory Of The Global Seismotectonic, Volcanic And Climatic Activity Of The Earth.” International Journal of Engineering Science Invention, 3(10), 22-58. 
http://www.slideshare.net/inventionjournals/e031022058.

[33] Sergey Victorovich Simonenko. (2017). "The Predictions Of The Thermohydrogravidynamic Theory Concerning The Strongest Intensifications Of The Global Natural Processes Of The Earth In 2017 Since 10 April, 2017 And Before 26 February, 2018.” Accepted for publication in the American Journal of Earth Sciences. In press.

[34] Hurricane Matthew is getting stronger. Associated Press. Oct. 6, 2016. AM. http://www.businessinsider.com/hurricane-matthew-getting-stronger-2016-10.

[35] Beno Gutenberg. (1927). Grundlagen der Erdbebenkunde, Germany, Berlin: Gebrüder Bornträger.

[36] Sergey Victorovich Simonenko. (2015). "The Practically Confirmed Validity Of The Forecasting Aspects Of The Deterministic Thermohydrogravidynamic Theory." American Journal of Earth Sciences, 2(5), 106-122. http://www.openscienceonline.com/journal/archive2?journalId=715\&paperId=2331.

[37] Sofia Lotto Persio. "Yellowstone Supervolcano Earthquake Swarm Hits More Than 1,200 Events." Tech \& Science. July 20, 2017.

http://www.newsweek.com/yellowstone-supervolcano-earthquake-swarm-hits-over-1200-events639816.

[38] Michael Safi. "India Floods: 213 Killed In Gujarat As Receding Waters Reveal More Victims." The Guardian. July 31, 2017. https://www.theguardian.com/world/2017/jul/31/india-monsoon-floods-gujarat-death-toll-over200.

[39] “Typhoon Noru Brings Heavy Rain To Japan, Injures 51.” AFP. August 8, 2017. https://www.yahoo.com/news/typhoon-noru-brings-heavy-rain-japan-injures-51-064709046.html.

[40] Rebecca Ratcliffe. "Floods Claim More Than 800 Lives Across India, Nepal and Bangladesh." The Guardian. August 22, 2017. https://amp.theguardian.com/global-development/2017/aug/22/floods-across-india-nepal-andbangladesh-claim-more-than-800-lives-south-asia.

[41] Frank Bajak. "Damaging Hurricane Harvey Settles In Over Southeast Texas." Associated Press. August 27, 2017. https://www.yahoo.com/news/damaging-hurricane-harvey-settles-oversoutheast-texas-082259260.html.

*Corresponding author.

E-mail address: sergeysimonenko@ mail.ru 